\title{
Sperm Retrieval
}

National Cancer Institute

\section{Source}

National Cancer Institute. Sperm Retrieval. NCI Thesaurus. Code C94427.

Any procedure that is used to collect sperm. 